\title{
PROYECTO DE EXCAVACIÓN Y RESTAURACIÓN EN DÓLMENES DE ALCÁNTARA (CÁCERES). SEGUNDA CAMPAÑA
}

\author{
THE EXCAVATION AND RESTORATION \\ OF THE DOLMENS OF ALCÁNTARA (CÁCERES). \\ THE SECOND SEASON
}

PRIMITIVA BUENO RAMÍREZ (*)

RODRIGO DE BALBÍN BEHRMANN (*)

ROSA BARROSO BERMEJO (*)

ANA BELÉN CASADO MATEOS $(*)$

M. ${ }^{a}$ AMPARO ALDECOA QUINTANA (*)

\section{RESUMEN}

La continuación de los trabajos de excavación y consolidación en los dólmenes del término de Alcántara, permite matizar y enriquecer los datos de la primera campaña. El grupo de Alcántara se confirma como de alto interés. De resultar completamente inédito por lo que se refiere a sus materiales y a la presencia de grafías megalíticas, se dibuja ahora como especialmente rico, con ajuares bien conservados. La situación de los mismos, su calidad y variedad de materias primas nos permiten proponer una serie de cuestiones sobre ubicación de los depósitos funerarios y, desde luego, sobre la capacidad económica de unos grupos sociales que se suponían pobres, retardatarios y marginales.

\begin{abstract}
The continuation of the excavation and consolidation projects in the megaliths of the municipality of Alcántara allows us to change and enrich the data of the first season. The Alcántara group of tombs is confirmed as of great interest. Although unpublished hitherto, they permit us to propose certain questions about the location of the funerary deposits and, indeed, about the economic capacity of

(*) Área de Prehistoria. Universidad de Alcalá de Henares, C/ Colegios n. ${ }^{\circ} 2.28801$ Alcalá de Henares.

El artículo fue remitido en su versión final el 13-III-99.
\end{abstract}

groups which have been thought to be poor, retarded and marginal.

Palabras clave: Cuenca del Tajo. Dólmenes de pizarra. Arte Megalítico. Neolítico Final. Campaniforme.

Key words: Basin of the Tejo. Megaliths in slate Art. Late Neolithic. Bell-Beaker pottery.

\section{INTRODUCCIÓN}

Esta sección sobre novedades arqueológicas de la revista Trabajos de Prehistoria, nos permite dar a conocer los resultados de la segunda campaña de trabajos de documentación arqueológica y restauración de monumentos megalíticos en Alcántara (Cáceres). Con anterioridad (Bueno Ramírez et alii, 1998) habíamos expuesto los primeros datos de un conjunto dolménico prácticamente inédito que nos reservaba grandes sorpresas. De los trabajos realizados en la campaña del 97 presentamos un desarrollo mayor en el informe preceptivo entregado a la Junta de Extremadura y en un artículo en el que se detallan los métodos y resultados de la excavación de los dólmenes de Maimón I y II y del dolmen de Juan Rón I (Bueno Ramírez et alii, e.p.). Esperamos que aparezca proximamente en la revista Ibn Maruan de Evora, en esa política de inter- 
cambio cultural y personal que muchos arqueólogos españoles y portugueses tenemos interés en promocionar.

\section{UBICACIÓN DE LOS MONUMENTOS. TERRITORIOS MEGALÍTICOS EN LA CUENCA ALCANTARINA DEL TAJO}

En nuestro trabajo anterior (Bueno Ramírez et alii, 1998: fig. 1) mostrábamos un mapa de situación de los dólmenes localizados en término de Alcántara a tenor de los datos procedentes de los diversos autores que se han ocupado del tema (Bueno Ramírez, 1987, 1994; Guillén Oterino, 1983; Montano, 1987). Esto nos permitía incidir en la situación geográfica de un grupo dolménico desconocido, uno de cuyos máximos intereses estriba en su patente relación topográfica, cultural y arquitectónica con los conjuntos dolménicos documentados en la ribera portuguesa del río Tajo (Cardoso et alii, 1997). Nuestros colegas portugueses han detectado en los últimos diez años más de 60 sepulturas megalíticas, algunos menhires, rocas decoradas y restos de hábitat al aire libre (Henriques et alii, 1993).

La zona de la que hablamos está mediatizada por la red hidrográfica del Tajo, río que en el mencionado sector corre fuertemente encajado en una fosa excavada en materiales paleozoicos que da a lugar abruptas laderas, configurando un paisaje agreste con orillas poco benévolas para el desarrollo de actividades humanas que, aún hoy, es difícil de traspasar. A veces, entre la penillanura y el fondo el cauce del río hay hasta $200 \mathrm{~m}$. de desnivel (Martinez de Pisón, 1977).

El principal paso se encuentra en el actual puente de Alcántara, de origen romano, aunque se conocen otros vados. No obstante, es de destacar que los megalitos ocupan el territorio próximo a las riberas del Tajo, no necesariamente sus zonas vadeables. Los que hemos excavado en esta campaña, Trincones 1 y 2 y toda la necrópolis anexa, se sitúan precisamente en las proximidades de las riberas más abruptas presididas por el Castro de Castillejo de la Orden (Esteban Ortega et alii, 1988) fechado en la II Edad del Hierro por sus investigadores, pero en el que nos descartamos una ocupación más antigua de carácter calcolítico a tenor de algunos materiales documentados en superficie.

Los ríos Salor, Alagón y Erjas completan la mencionada red hidrográfica asentada sobre piza-
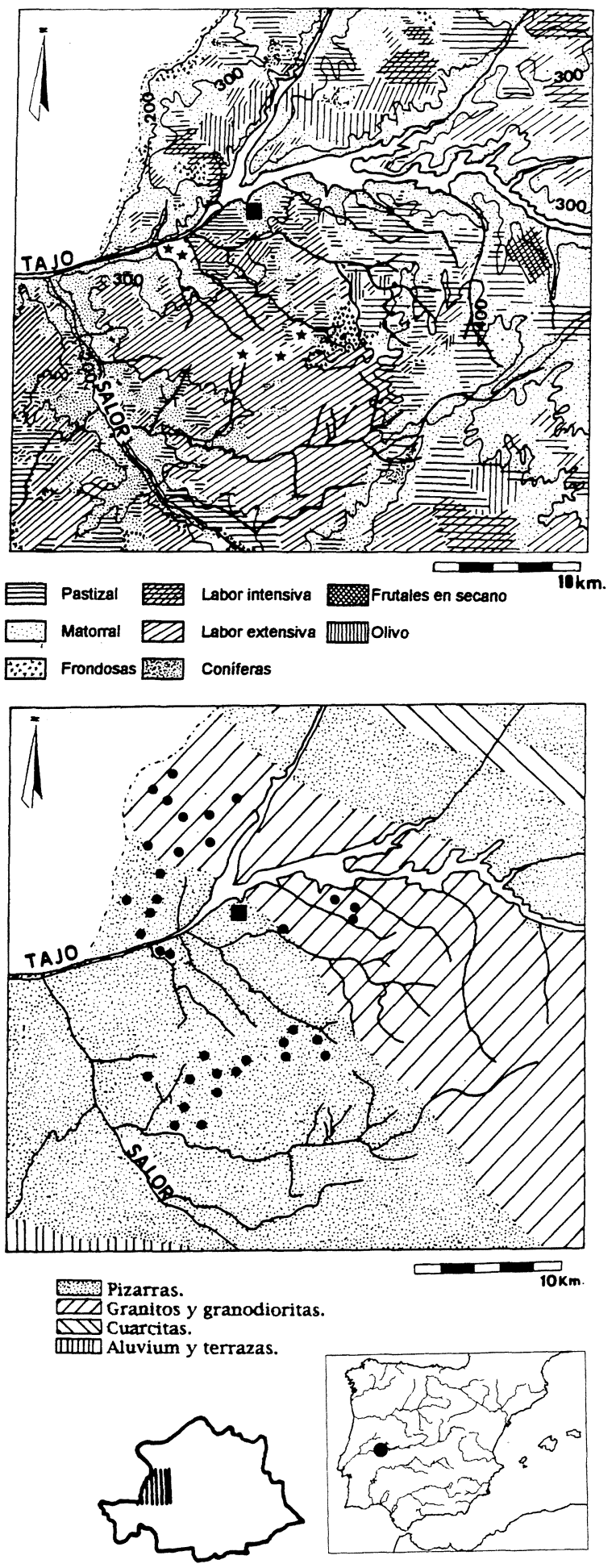

Fig. 1. Aprovechamiento de suelos en término de Alcántara (Cáceres) y sustrato geológico. Consta la situación de los dólmenes localizados en el término $(\bullet)$, destacándose la de los excavados esta campaña con una estrella. Un cuadrado sitúa la población de Alcántara. 
rras, terreno de una impermeabilidad notoria que hace que éstos vayan aumentado en caudal a lo largo de sus cursos.

Traspasados los sectores de ribera, el paisaje se caracteriza por una planicie apenas accidentada en la que dominan pizarras y granitos. Forma un continuum entre Alcántara, Garrovillas, Trujillo y Cáceres (Bodega Fernández y Gutiérrez Ronco, 1978). Este es uno de los hechos más representativos del relieve del occidente peninsular y en dicha planicie, por lo que al término de Alcántara se refiere, se localizan la mayor parte de los dólmenes hasta hoy documentados, junto con un par de yacimientos de grabados al aire libre (Montano Dominguez e Iglesias Álvarez, 1988) que nos hacen sospechar la extensión del conjunto portugués del Tajo. La generalidad de los sepulcros no sobrepasa los $300 \mathrm{~m}$. de altitud sobre el nivel del mar, al igual que sucede en otros conjuntos megalíticos próximos como Santiago (Bueno Ramírez, 1994: 43) y Valencia deAlcántara (Bueno Ramírez, 1988: 187), en España o los megalitos de la Beira interior portuguesa (Cardoso et alii, 1997: 207).

El término de Alcántara comparte la misma base geológica con la presencia de pizarra en su sector meridional que se extiende hacia los términos de Herrera, Santiago y Valencia de Alcántara y hacia los de Cedillo y Brozas. En todos ellos disponemos de datos que confirman la presencia de monumentos de pizarra de características similares a los alcantarinos (Bueno Ramírez, 1988, 1989 y 1994; Oliveira, 1994). Hacia el norte, predominan granitos lo que se traduce en monumentos fundamentalmente realizados en este material, como el dolmen de la Puente o el que tenemos previsión de excavar en la campaña de 1999, de los Marvanes. A veces, el granito aparece mezclado con lastras cuarcíticas como en el conjunto del Retamar que también proceden del sustrato geológico de la zona.

La reconstrucción del aprovechamiento de suelos se basa en los mapas actuales que delimitan, en la zona meridional de la localidad, terrenos de labor extensiva sobre suelos pobres y pastizal que se dibujan como una mancha alargada y flanqueada al Oeste por terrenos de matorral en los que aún no hemos documentado ningún dolmen. Esta dedicación se diluye en el sector norte de Alcántara con base granítica, en favor de terrenos de labor intensiva con mejores suelos, y algunos núcleos de pastizal que coinciden bien con la situación del Menhir del Cabezo y dólmenes próximos (Bueno Ramírez et alii, 1998; fig. 1). La mancha de terre- no de labor extensiva alcanza hasta Piedras Albas (Bueno Ramírez, 1987a), municipio menos prospectado pero del que también conocemos noticias que permiten sospechar una ocupación megalítica (Fig. 1). No hay que olvidar que los únicos datos polínicos de que disponemos nos hablan de dehesas dedicadas a pasto en los sustratos pizarrosos como el de Santiago de Alcántara y en los suelos con base granítica como los de Valencia de Alcántara (Lopez, 1994: 97-98) y de una mayor humedad como indicaría la presencia de Castaño en los sepulcros de Retamar (Guillén Oterino, 1983). Estos datos acercan más las posibles explotaciones de uno y otro territorio, siendo el pasto -más o menos proteico- y los cultivos, la dedicación tanto de unos como de otros. Con los datos actuales, no nos parecen sostenibles las hipótesis que inciden en diferencias muy marcadas (Oliveira, 1997: 360) que creasen una "frontera" entre las tierras con sustrato geológico granítico, y las de sustrato pizarroso. La ocupación generalizada de estos territorios, con mayores o menores posibilidades agrícolas y de pasto, nos parece más en relación con el aumento demográfico constatado a partir de la transición IV/ III milenio a.C. en todo el Suroeste, que empuja a grupos que necesitan gran cantidad de tierras para su aprovisionamiento, a ocupar todo el terreno disponible.

Las áreas de aprovisionamiento de materias primas utilizadas para la construcción de los dólmenes están muy próximas. Nos referimos evidentemente a pizarras, granitos y cuarcitas. Respecto a las que hemos documentado formando parte del ajuar habría que diferenciar entre la industria tallada en sílex, pizarra, cuarzo y cuarcita que igualmente creemos de procedencia próxima, los gabros dioríticos u olivínicos y dioritas sobre los que se ha realizado una industria pulimentada de gran calidad, materias en general extraíbles en contextos graníticos y la inmensa variedad de materias primas documentadas en los elementos de adorno y en las placas decoradas, que merecen un capítulo aparte.

Los adornos componen un amplio conjunto de cuentas de collar de variadas tipologías, colgantes e incluso restos de un brazalete y sus materias primas engloban desde la pizarra de la última pieza señalada, hasta una enorme variedad de piedras de color. La famosa piedra verde está presente, ya sea en sus versiones más compactas tipo variscita, ya en sus versiones más translúcidas, tipo jadeíta, como las documentadas en el ajuar de los sepulcros 
próximos de Garrovillas, conservado en el Museo de Cáceres (Bueno Ramírez 1994: 66). Hay algunas piezas de azabache de muy buena calidad que nos remiten a ejemplares localizados en las excavaciones de Valencia de Alcántara y, como entonces señalábamos, a zonas de extracción de Zamora o del Norte de la Península Ibérica (Bueno Ramírez, 1988: 175, 182, 205). En la actualidad estamos aún en una fase de estudio de todo este material, pero las apreciaciones que podemos extraer a simple vista nos permiten esbozar la idea de que en Alcántara se concentran grupos humanos con capacidad importante de intercambio de materias primas de prestigio, con lo que esto supone a la hora de valorar el contexto social y cultural de estas gentes.

Las placas decoradas, además de estar realizadas en esquisto, la materia prima más corriente en estas producciones, poseen ejemplos en arenisca de forma y tratamiento muy similar al de casos portugueses próximos, e incluso en calizas de color blanquecino y aspecto blando que igualmente conecta estos ejemplares alcantarinos con las del próximo sector beirano.

La mayor parte de los ajuares recuperados hasta el momento pertenece a momentos de Calcolítico pleno, siendo la cerámica campaniforme, incisa y lisa, la definitoria de esta cultura en los contextos dolménicos a los que nos referimos. El metal en esa época es sobradamente conocido en la Extremadura española y la zona de Alcántara no constituye una excepción. En la campaña de 1997 documentamos una placa metálica asociada al depósito campaniforme liso de Juan Rón I (Bueno Ramírez et alii, 1998: 177) que nos ratifica en dicha idea.

Las fuentes de aprovisionamiento de metal, concretamente cobre, de este sector se localizan en Plasenzuela en las proximidades de Cáceres y, siguiendo el Alagón, en las Hurdes o, más al Norte en Zamora -lugar del que podría proceder la variscita- o, hacia el interior, en la sierra del Guadarrama (Mapa Metalogenético de España). A ello hay que añadir los vestigios de estaño del sector Piedras Albas-Garrovillas-Arroyo de la Luz-Cáceres (Florido Laraña, 1987: 31-88). No hemos de olvidar las posibilidades de una explotación local de placeres fluviales aúreos (Sánchez Palencia, 1989: 48), algunas de ellas constatadas a orillas del Salor (Florido Laraña, 1987: 90-94), que creemos de gran interés para explicar parte de las posibilidades de excedente que parece generar este conjunto social.

T. P., 56, n. ${ }^{\circ} 1,1999$

\section{EXCAVACIÓN Y CONSOLIDACIÓN DE LOS SEPULCROS DE TRINCONES. CAMPAÑA DE 1998}

En la finca de Trincones se conocían desde las primeras prospecciones de Fernando Tostado (Bueno Ramírez et alii, 1998: 172) dos arquitecturas muy próximas. En algunas referencias, dichos monumentos aparecen recogidos como Los Castillejos.

El planteamiento general de nuestro trabajo partía de la base de la evidente relación topográfica entre uno y otro dolmen, por lo que los cortes se realizaron en conjunto, con un mismo Punto Cero (P.0.) con objeto de tener un análisis global de ambos monumentos. La mencionada diferencia volumétrica se corresponde claramente con la nítida diversidad del perímetro y alzado de ambos túmulos (Fig. 2).

En Trincones 1 trazamos un corte de $13 \mathrm{~m}$. (E/O) $\times 14 \mathrm{~m}$. $(\mathrm{N} / \mathrm{S})$ que, posteriormente, fue ampliado, $y$ al Este otro en Trincones 2 de $5 \mathrm{~m}$. (E/O) $\times$ $4 \mathrm{~m}$. (N/S). Entre ambos, cuadriculamos una zanja intermedia con objeto de averiguar si existía algún resto de habitación o de cualquier otra actividad, que resultó completamente improductiva. Los cortes mayores se dividieron a su vez en subcuadrículas con referencia a Cámara, Corredor, Túmulo yAtrio.

Excavamos levantando capas de $5 \mathrm{~cm}$. Los objetos se numeran correlativamente y se guardan en un recipiente propio con una ficha individualizada que incluye su lugar de procedencia, capa de la que se ha extraído, situación en la cuadrícula y cota respecto al P.0. De todo el proceso se levantan planos y se toma documentación gráfica en diapositiva color, Polaroid y en video, soportes que permiten su tratamiento por ordenador.

El monumento 1 se presenta como una cámara con corredor largo, atrio abierto y túmulo com-

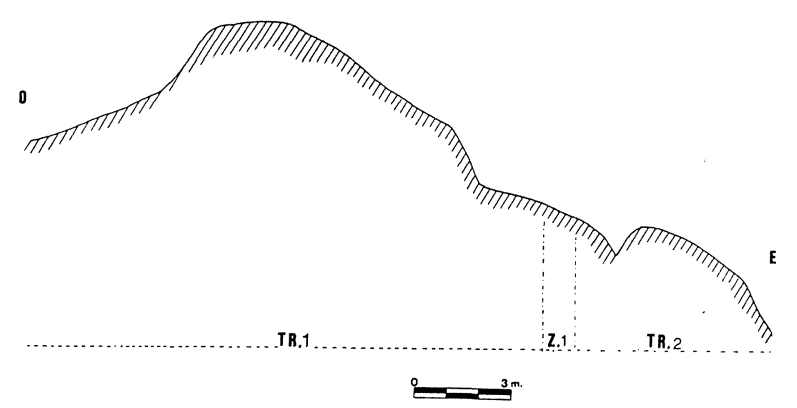

Fig. 2. Perfil de los dólmenes de Trincones 1 y 2 y Zanja Intermedia. 
puesto por piezas de pizarra de tamaño medio y delimitado por piezas mayores situadas en sentido vertical o pseudo vertical.El dolmen estaba prácticamente cubierto por la construcción de un chozo moderno y aunque podía verse algo del desarrollo del corredor, el recorrido total de éste, la presencia de atrio y la delimitación completa del túmulo han podido conocerse con los trabajos de excavación.

El monumento 2 se sitúa a escasos $10 \mathrm{~m}$. al este del anterior y es una cámara de pequeño tamaño rodeada por un túmulo igualmente reducido. La altura máxima de los ortostatos de pizarra de la cámara es de 1,05 m., su diámetro es de 1,40 m. y el contorno tumular tiene un diámetro de $5 \mathrm{~m}$. Parte de este contorno conserva restos de una delimitación pétrea como la del monumento mayor. Trincones 2 estaba mal conservado y sus ortostatos habían sido removidos. Esto explica la escasez de material localizado, prácticamente en su totalidad piezas talladas de pizarra, que quizá permanecían aún en la cámara porque no se les dió ningún valor por parte de los destructores del monumento.

Frente a la pobreza de resultados de la excavación de Trincones 2, Trincones 1 se reveló como un monumento de importancia, con un ajuar excepcional, una parte importante del cual se encontrabain situ, y con grabados megalíticos como los que documentamos en la campaña de 1997 en otros dólmenes del término (Bueno Ramírez et alii, 1998: 179).

Para delimitar el contorno de la Cámara comenzamos por levantar la acumulación de piedra mencionada. Tomamos cotas de la cámara tras esta limpieza y realizamos una planta de Superficie del monumento.

Las tres primeras capas que levantamos a continuación demuestran lo afectado que ha quedado este sector del monumento con la realización del chozo. Aparecen muchas piezas de pizarra de tamaño medio, que creemos pertenecen a la construcción moderna, y entre ellas algunas piezas del ajuar. En la primera capa, éstas son muy escasas, en la segunda poseen el interés de albergar un fragmento de campaniforme y en la tercera, abundan de modo notable. Precisamente al limpiar esta capa 3 de la Cámara, se dibuja el extremo de dos lajas de pizarra que nos aconsejan establecer un nuevo nivel y separar los materiales. Agrupamos, pues, las primeras capas en un Nivel I de acumulación de restos que no se encuentran in situ y que interpretamos como resultado de la remoción del nivel posterior o Nivel II (Fig. 3).

La interpretación cronológica de este primer
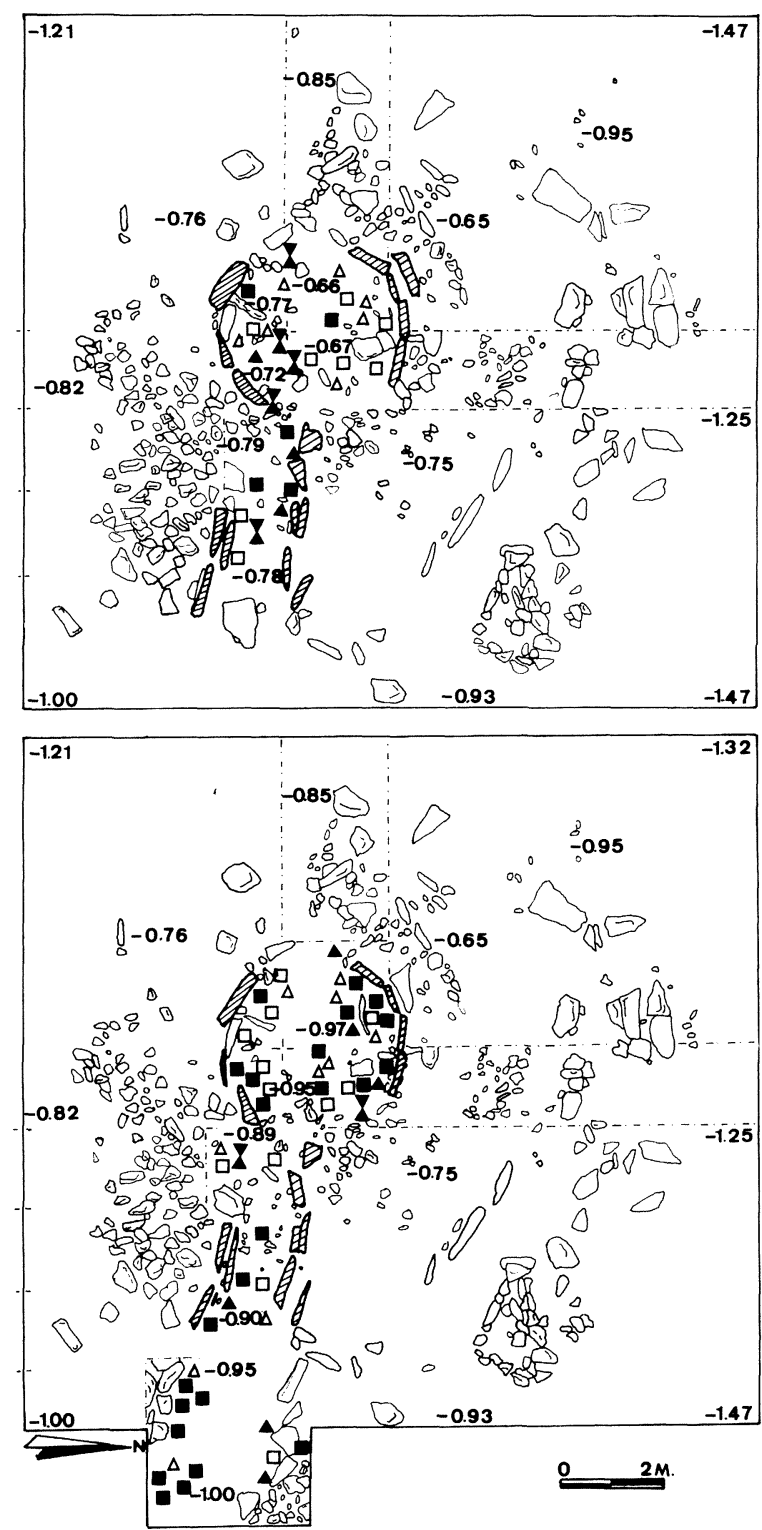

Fig. 3. Planta con situación de los hallazgos de los Niveles I y II de Trincones 1 (Alcántara. Cáceres).

nivel de la Cámara es fácil a tenor del hallazgo de campaniforme, lo que lo sitúa en el II milenio a.C. con el interés de que los hallazgos campaniformes en dólmenes extremeños son sumamente escasos. Nuestros descubrimientos del año anterior en el dolmen de Juan Rón I (Bueno Ramírez et alii, 1998: 177) y los que ahora recogemos, ratifican estas ocupaciones en el término de Alcántara.

En el Nivel II incluimos las capas 4, 5 y 6, sucesivas limpiezas que abarcan desde el comienzo de los ortostatos fragmentados hasta que llegamos a su

T. P., 56, n. ${ }^{\circ} 1,1999$ 
base y podemos levantarlos. Es apreciable una cantidad mayor de materiales que en el Nivel I, con una incidencia notable de puntas de flecha, las cuales tienden a situarse junto a los ortostatos. Son abundantes también los hallazgos de cuentas de collar y comenzamos a localizar algún pulimentado.

No tenemos la certeza de que los materiales de este Nivel II estén in situ. Aún así hay argumentos para pensar que nos encontramos ante un resto de nivel original de deposiciones, algo mezclado por la propia caída de la parte superior de los ortostatos que hemos mencionado y por el agujero realizado en época reciente en el sector $\mathrm{C} 4$ de la cámara, remociones explicables por la construcción de la cabaña.

El levantamiento y despeje de los fragmentos de los ortostatos coincide prácticamente con la aparición de unas lajas planas de pizarra que son parte de la cubierta original. A partir de aquí delimitamos la capa 7 de la cámara, que equivale al Nivel III de ia misma, a efectos metodológicos.

En el momento en que podemos documentar bien el tamaño y forma de las losas de cobertura, diferenciamos una capa 8 o Nivel IV de nuestra interpretación, cuyo significado es similar al de la capa 7. En todo caso, las capas 7 y 8 serían un unicum asociado a la caída de las losas de cobertura, a las que quizá habría que añadir los hallazgos de la capa 6 , siendo los de las capas 1,2 y 3 restos más o menos movidos de ese mismo depósito (Fig. 4). Los hallazgos de la capa 8 repiten lo que venimos mencionando: cuentas, algunas puntas, pulimentados y vasijas enteras o casi enteras.

La limpieza de este nivel deja al aire un suelo muy duro -nuestro NivelV-con un grosor considerable según las zonas de la cámara, que creemos producto de una preparación específica en la que ha debido tener parte algún calentamiento de sus componentes. Dentro de este suelo se observan huesos y cerámica. Es muy posible que haya también restos de industria lítica, pero tendremos que disgregarlo en laboratorio para saber qué contiene con exactitud. Esta capa tiene una consistencia de cemento y a lo que más recuerda es al tradicional mortero. Es sin duda un sello perfecto entre las capas mencionadas con anterioridad y el nivel inferior a este suelo. En la parte central de dicho suelo se observan los restos de una hoguera de $54 \mathrm{~cm}$. de diámetro, la cual podría haber formado parte del proceso que se llevó a cabo para igualar el mismo (Fig. 5).

La costra, que es la palabra que mejor lo define, se percibe nítidamente en una parte importante de
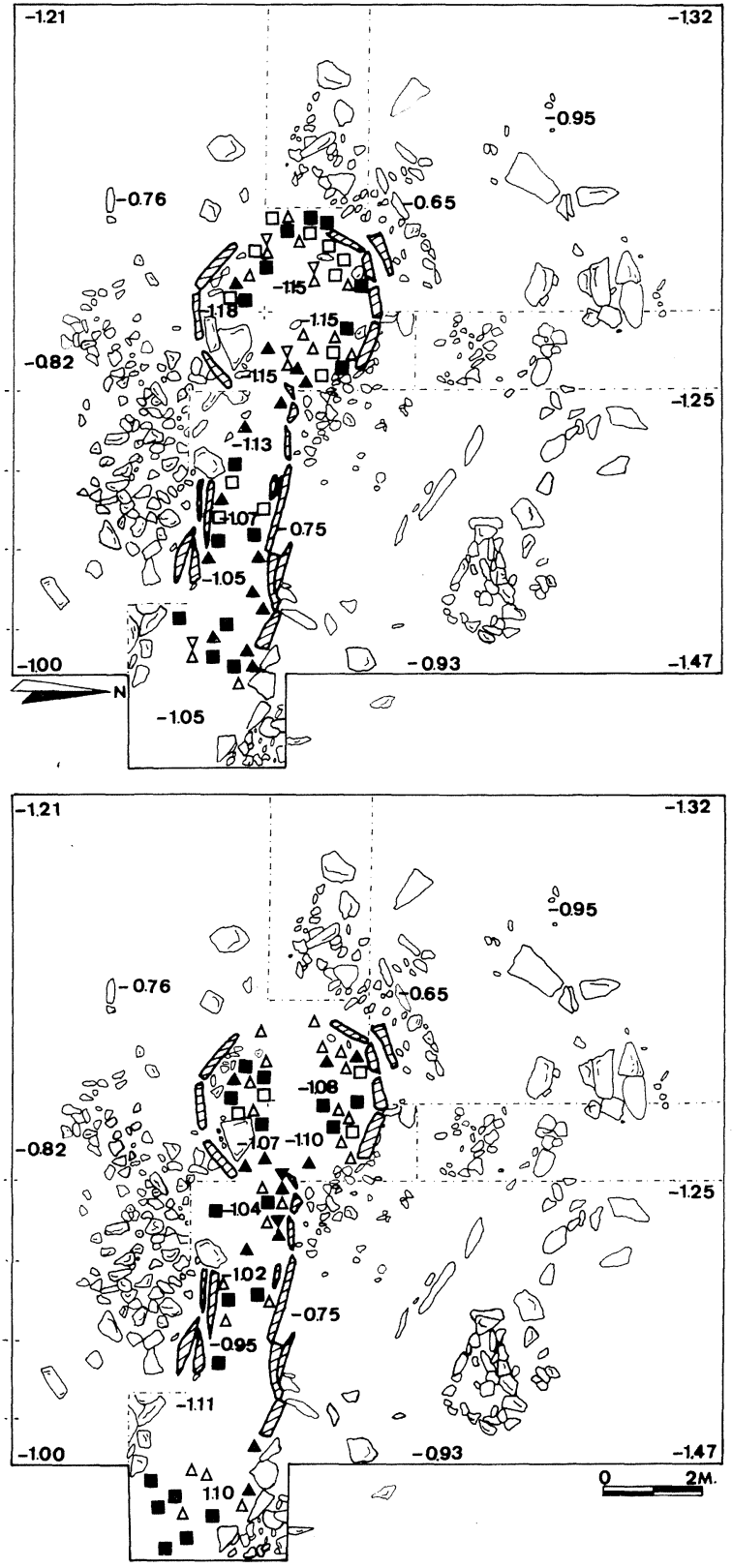

Fig. 4. Planta con situación de los hallazgos de los Niveles III y IV de Trincones 1 (Alcántara. Cáceres).

$\mathrm{C} 1$, en $\mathrm{C} 2$, en parte de $\mathrm{C} 3$ y en $\mathrm{C} 4$. Una vez extraído este suelo continuamos la excavación acotando una capa 9 que se corresponde con nuestro NivelVI. Muchas de las piezas que recogemos en este nivel están nítidamente incrustadas en la irregular superficie de la pizarra de base.

La construcción del monumento supuso llegar hasta la pizarra basal en la cual no sólo se encajaron las fosas de los ortostatos, sino que se incluye- 


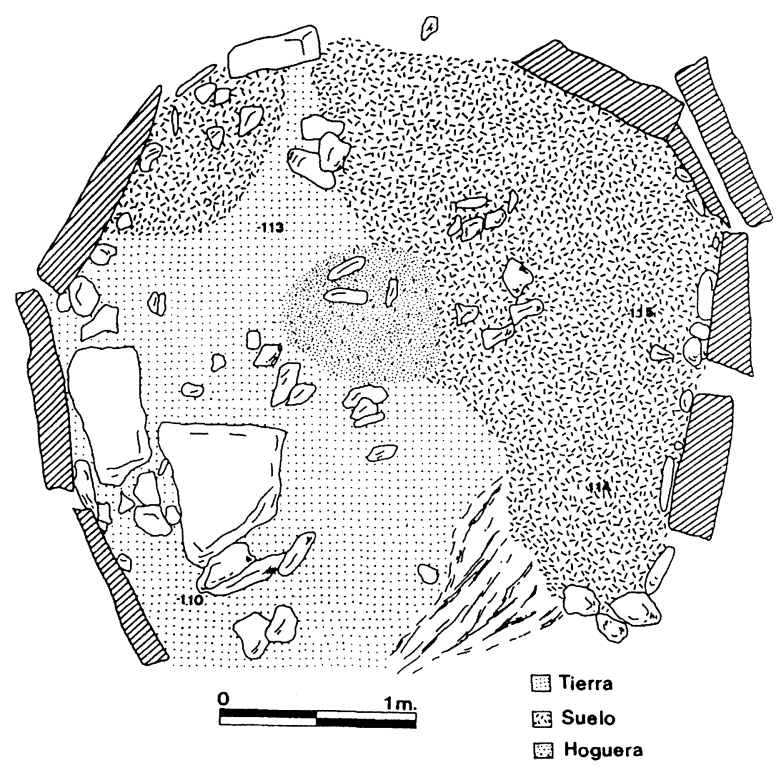

Fig. 5. Detalle del suelo de la Cámara de Trincones 1 (Alcántara. Cáceres). Nivel V.

ron algunos materiales. Llama la atención la presencia de algunas formas circulares. Una en la zona central de la cámara y dos en en C1 en las que localizamos materiales. La pequeña estructura de la zona central de la cámara es casi circular y podría haber servido para colocar algún elemento antropomorfo, decorado o no, a tenor de la constatación de otro que tenemos a la entrada del corredor, igualmente hincado en la pizarra basal.

La pizarra y sus formas naturales han jugado un papel en la disposición de los depósitos iniciales (Lám. I). Este hecho es muy notorio en la presencia de un canal central que se localiza en la cámara y que se sigue por todo el corredor. En él, se han

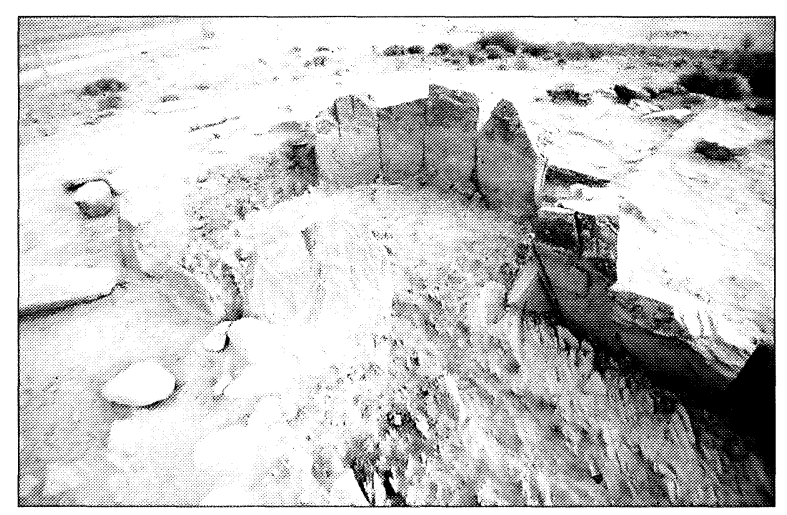

Lám. I. Cámara y parte del corredor de Trincones 1. Detalle de la base de pizarra. Foto R. de Balbín.
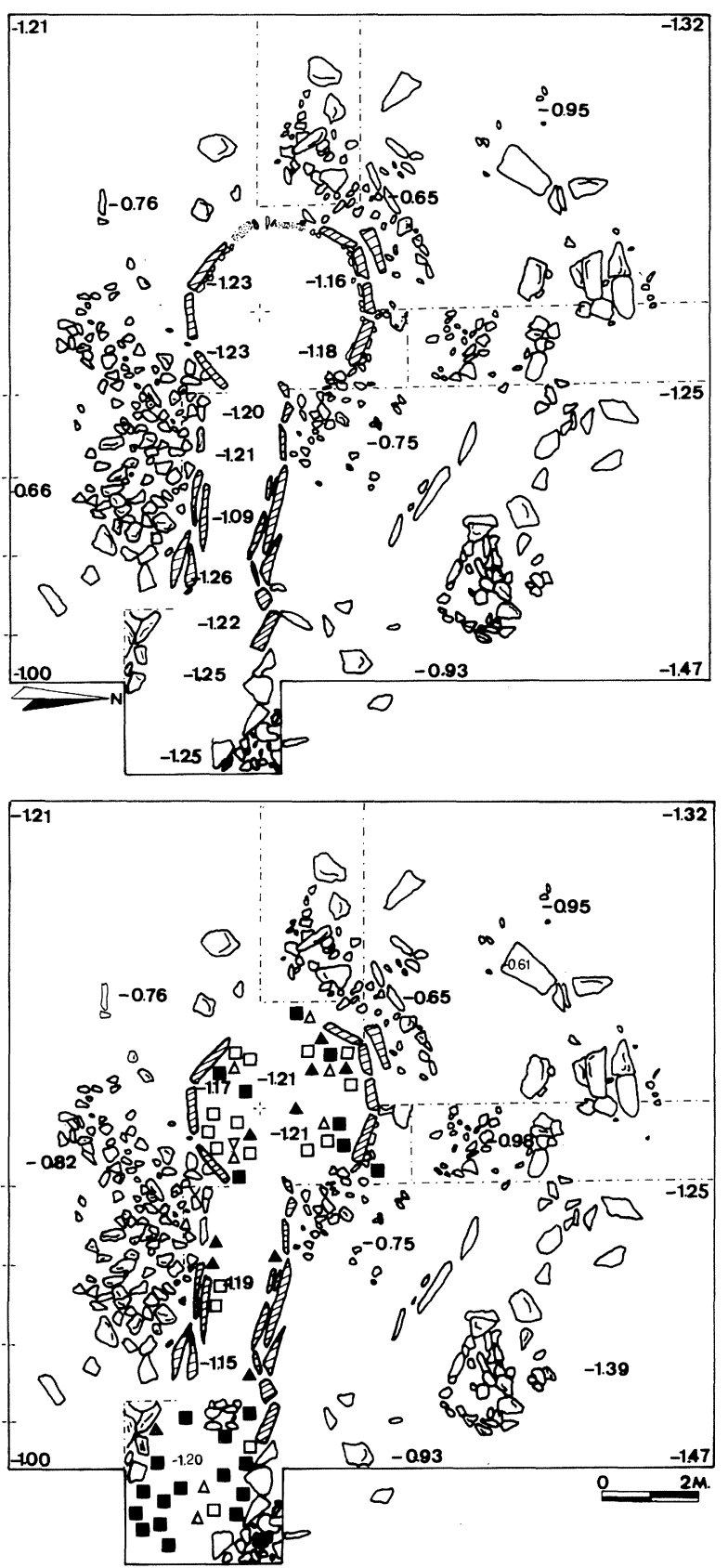

Fig. 6. Plantas con situación de hallazgos del Nivel VI y el estado final del monumento de Trincones 1 (Alcántara. Cáceres).

situado una parte importante de los cuencos y placas de las capas 8 y 9 de la Cámara y de las hachas, cuencos y placas de los niveles V, V Base y VI del corredor.

No es un caso único en los dólmenes del Suroeste. Nosotros hemos tenido ocasión de constatarlo personalmente en la reexcavación y limpieza de 


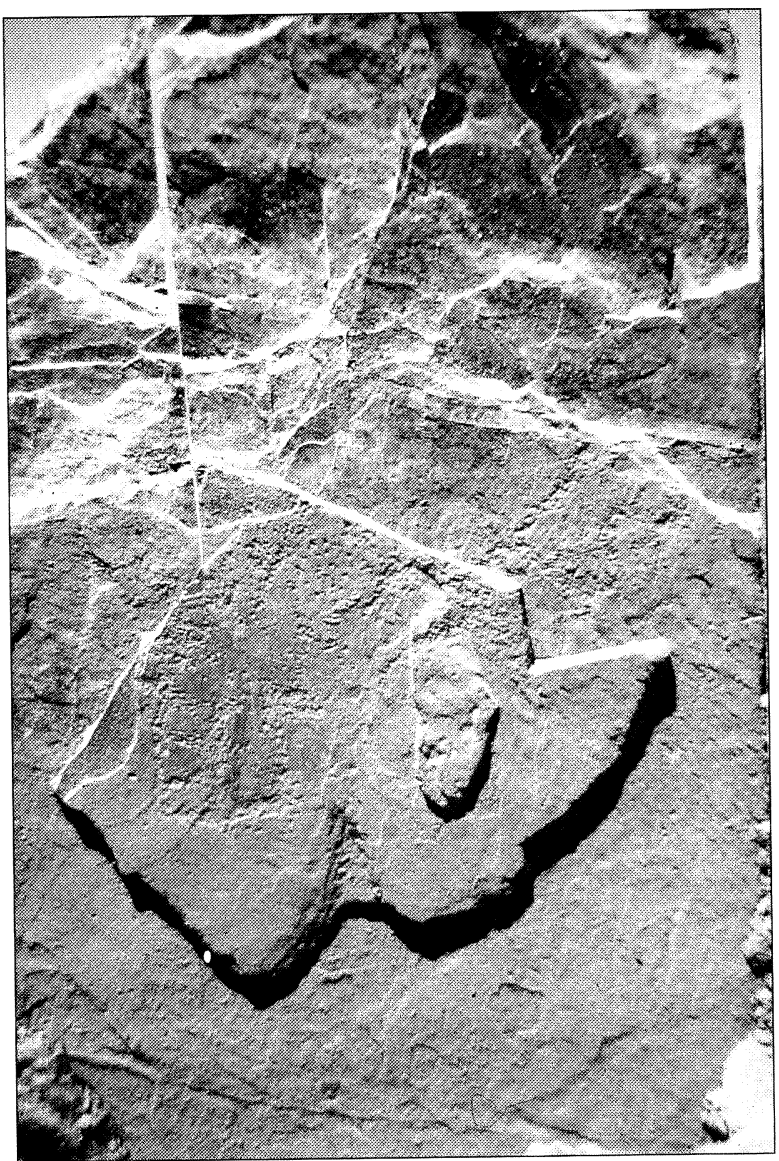

Lám. II. Piqueteados del ortostato 7 de la cámara. Foto R. de Balbín.

los dólmenes del Pozuelo (Huelva) y los Leisner (1951) mencionan una disposición similar en algunos monumentos de Reguengos.

Arquitectónicamente, la cámara se define como una estructura circular de $3,5 \mathrm{~m} . \times 3 \mathrm{~m}$. de diámetro en la que faltan dos ortostatos en su zona frontal, cuyas fosas pudimos delimitar en nuestro corte "Cámara Ampliación Oeste". La cámara debió estar formada, por $10 \mathrm{u} 11$ ortostatos ubicados uno junto a otro. La inclinación de los que forman parte del lateral Sur de la Cámara nos parece relacionada con la intrusión localizada en esta zona, entre la cámara y el corredor, que obligó a forzar la posición de la losa 3 , empujando probablemente en su caída a la 4 y la 5 .

Los ortostatos son de pizarra y en su mayor parte tienen la superficie externa muy deteriorada debido a la exfoliación natural de la pizarra. Sólo las zonas que conservan su superficie original tienen grabados piqueteados conservados. Esta conserva-

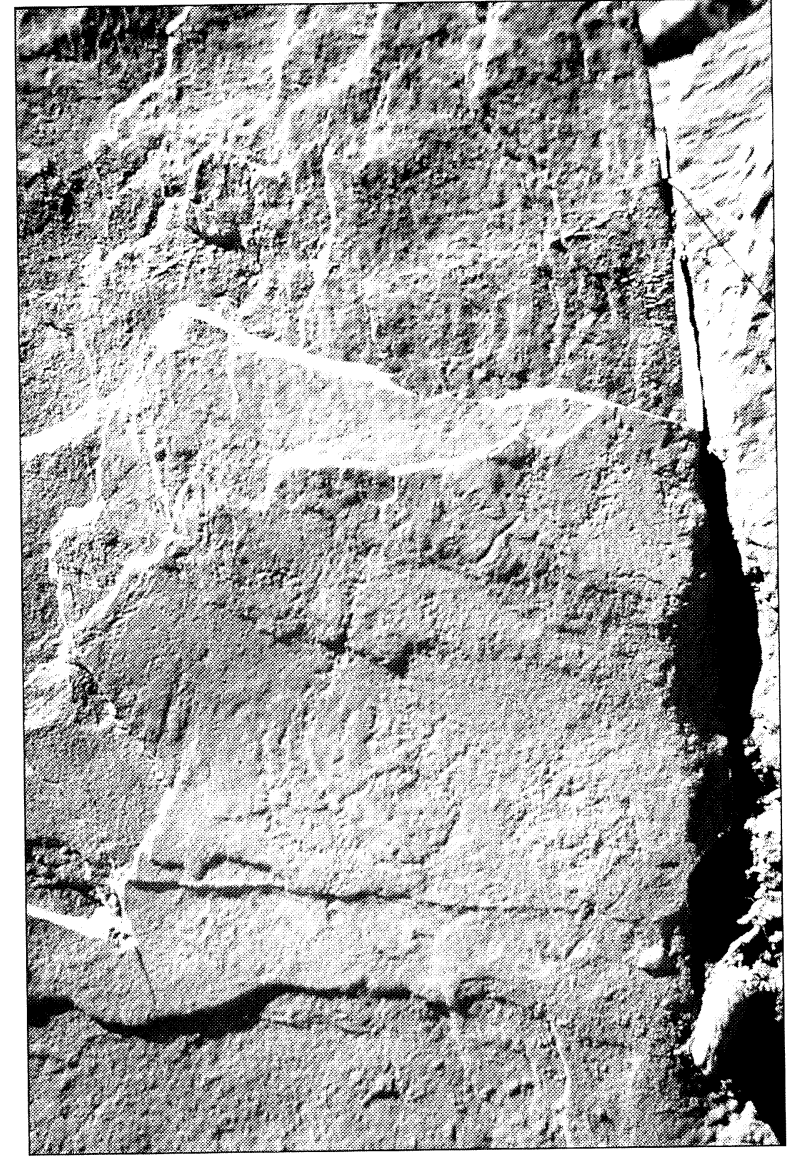

Lám. III. Ojos soles piqueteados del ortostato 9 de la cámara. Foto R. de Balbín.

ción diferencial en relación directa con el sistema de exfoliación de la materia prima de los ortostatos, es muy evidente. De hecho, las piezas aún decoradas sólo lo están en una parte, la que es corteza externa. El resto ha caído y por tanto, la decoración conservada no es completa (Lám. II y III). La técnica documentada es el grabado, pero no descartamos que en origen la pintura hubiese tenido un papel importante, pues hemos localizado placas antropomorfas con abundantes restos de pintura roja y paletas de ocre, tanto en la cámara como en el corredor, cuya presencia no se explica sino es porque se ha pintado el "escenario" de la muerte. Algunos dólmenes pintados recientemente documentados como el de Alberite poseen entre su ajuar una paleta de ocre con gran cantidad de colorante (Ramos Muñoz y Giles Pacheco, 1996: 140).

La altura máxima de la cámara es de $1,20 \mathrm{~m}$. en el ortostato 8. Durante su utilización, el dolmen tenía un alzado interior próximo al metro (Fig. 7), 

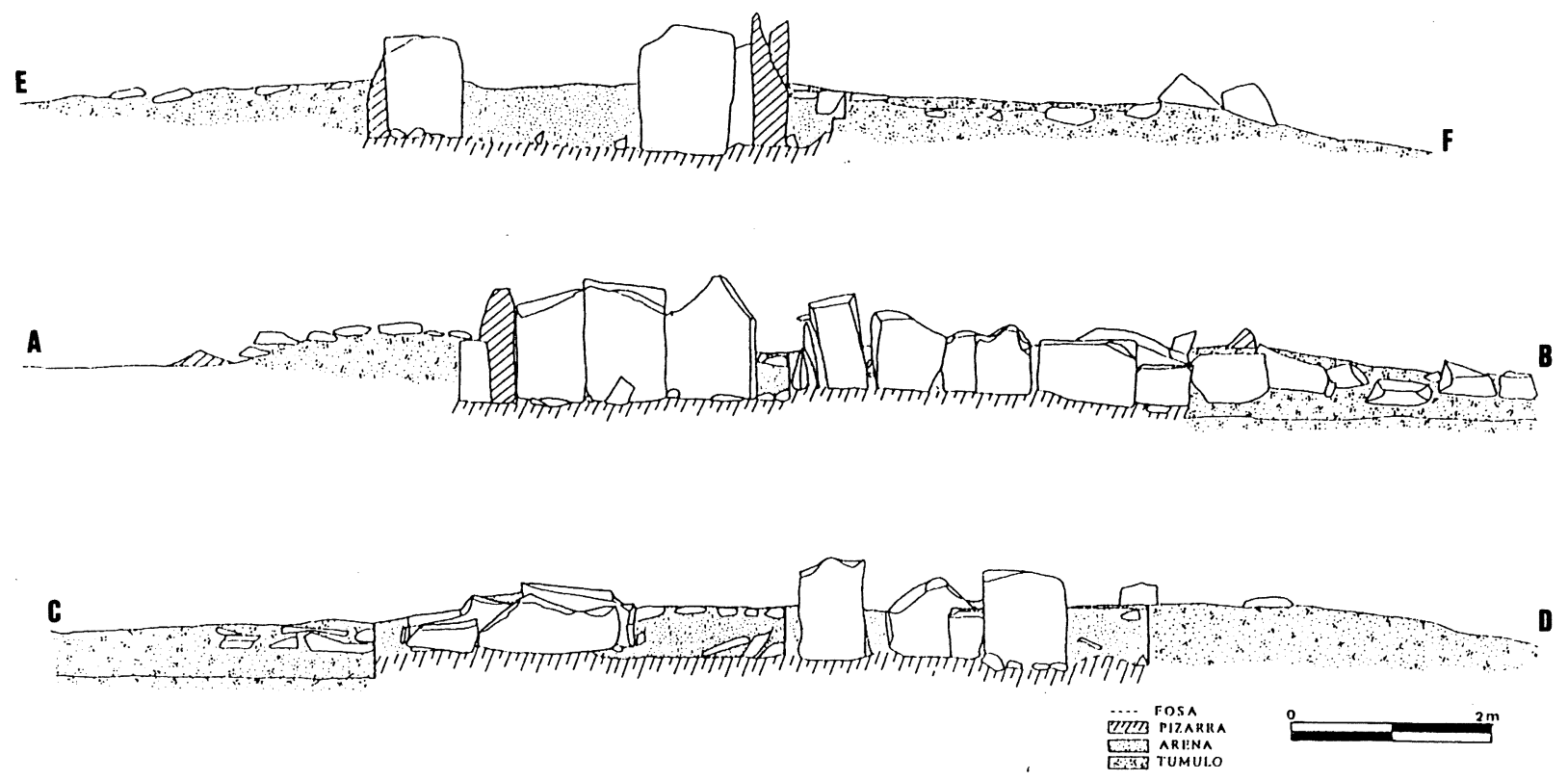

Fig. 7. Alzados del dolmen de Trincones 1 (Alcántara, Cáceres).

lo que a tenor de los datos que conocemos en la generalidad del megalitismo del Suroeste, es una altura bastante escasa (Bueno Ramírez, 1994: 4748). Los ortostatos se han incluido en una fosa tallada en el terreno y se ha reforzado su posición con calzos también de pizarra, de tamaño medio.Algunos están muy bien conservados, como los del ortostato 6.

El descubrimiento de unos fragmentos de cubierta es otro de los elementos de mayor interés cultural de los que ha aportado la excavación de este monumento.

Las losas planas localizadas en nuestra capa 8 podrían ser interpretadas como restos de un enlosado. De hecho, los enlosados son conocidos en este tipo de sepulcros (Oliveira, 1994), pero las piezas que los forman son de menor tamaño y están más en relación con las que nosotros mismos documentados en la excavación de Maimón 2 (Bueno Ramírez et alii, 1998: fig. 5). Las losas de Trincones 1 son de un porte considerable, no tienen continuación en el resto de la Cámara, pese a que en ese nivel consideramos que el sepulcro se encuentra en su estado original, y una vez sacadas a la superficie, encajan entre sí formando una figura semicircular que entendemos como parte de una cubierta de tendencia paracircular, al igual que las conocidas en otros monumentos graníticos de la zona (Bueno Ramírez, 1988: 162), y que se caracterizan por estar retocadas en sus laterales para obtener la forma mencionada, como sucede en nuestras losas de Alcántara.

La cuestión de la cobertura de estas cámaras ha estado ligada al hecho de su diámetro amplio, a la existencia de más de siete ortostatos en la cámara $\mathrm{y}$ al condicionamiento del esquisto como materia prima. Los dos primeros argumentos: el amplio diámetro y el número de ortostatos, servían para proponer la existencia de falsas cúpulas, como única cobertura posible, teoría que hemos descartado en otros trabajos (Bueno Ramírez, 1987a, 1991). El que el esquisto impida obtener lajas de tamaño suficiente para conseguir cubiertas monolíticas (Cardoso et alii, 1997a: 11) posee argumentos contrarios en el mismo conjunto alcantarino: el dolmen de Juan Rón I (Bueno Ramírez et alii, 1998: 180) de buen tamaño, realizado en esquisto y que conservaba al interior de la cámara una parte importante de la cubierta del monumento. Este hecho, junto a los datos que hemos obtenido en Trincones 1 nos permite afirmar que estas cámaras estuvieron cerradas con cubiertas pétreas planas, al menos en muchos ejemplares.

La riqueza en cantidad, variedad y conservación de los materiales exhumados es muy notoria. De la cámara proceden unas quinientas piezas.

El corredor estaba menos afectado por la construcción que ocupa casi exclusivamente la Cámara. Una vez limpio y retirado el ramaje, comienzan a delimitarse piedras de pizarra de tamaño medio y 
pequeño y aparece algo de material. Ésta es nuestra capa 1. Las dos capas sucesivas, 2 y 3 , muestran un cierto revuelto de piedras y materia megalítico. Pronto se delimita en el primer tramo del lateral Sur, un ortostato caído, por lo que diferenciamos una capa 3.

Las tres capas descritas quedan incluidas en un nivel general que denominamos Nivel I que coincide con el descrito en la Cámara.

En la capa 4, los hallazgos se extienden a todos los tramos del corredor, y aunque salen algunas puntas, las láminas poseen un papel no documentado en la Cámara. Destaca la presencia de un fragmento de placa con ojos en relieve y restos de pintura roja. Esta capa del Corredor constituye nuestro Nivel II y la asociamos a los hallazgos de la Cámara de las capas 4,5 y 6 .

Limpia la capa 4, separamos una capa 5 , en la que se incrementan los hallazgos, siendo la situación de los mismos muy claramente interpretable como la de un depósito original que en su mayor parte se encuentra in situ, muy especialmente en lo que se refiere al primer tramo del Corredor o CO. 1.

En éste comienzan a aparecer un conjunto de pulimentados (Lám. IV) situados bajo el ortostato del lateral Norte y una serie de placas, en esa misma zona y hacia la Cámara, todo ello acompañado por dos vasos cerámico completos (Fig. 8). La situación de este depósito es excepcional pues los pulimentados se solapan unos con otros formando una acumulación expresa. Son piezas completas, sin huellas de uso y muy bien conservadas.

Una de las piezas mezclada con los pulimentados es una placa rectangular, con una de sus superficies cóncava, pulida y con huellas evidentes de

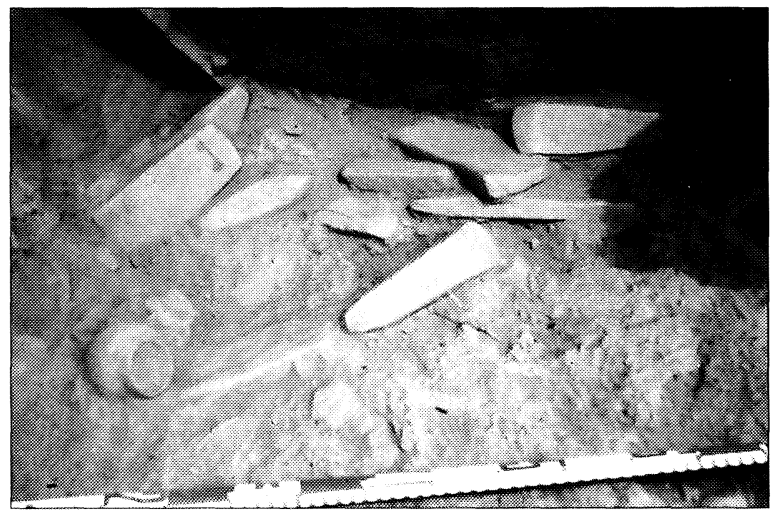

Lám. IV. Inicio del depósito del corredor de Trincones 1 (Alcántara, Cáceres).
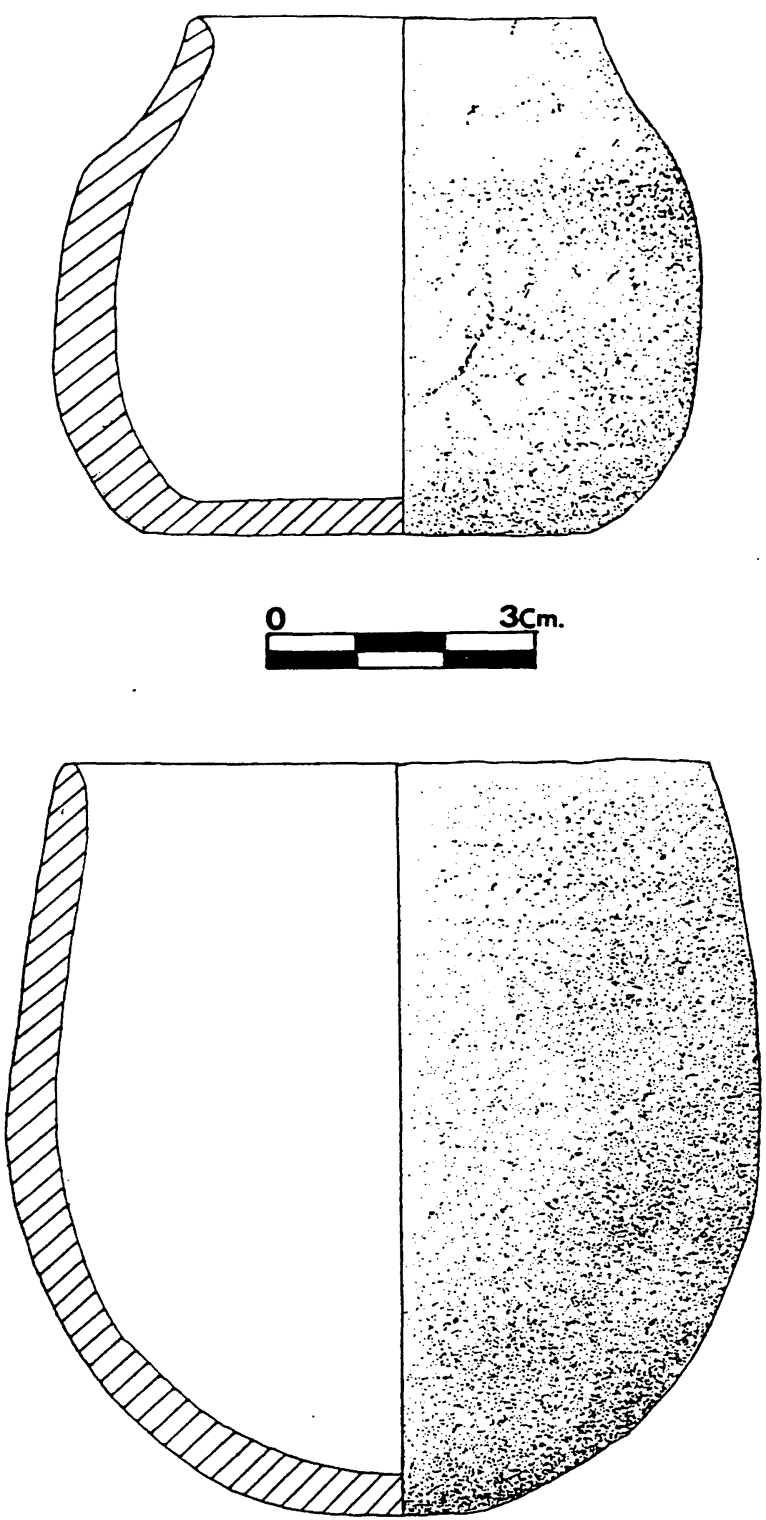

Fig. 8. Vasos del corredor de Trincones 1 (Alcántara, Cáceres).

color. La interpretamos como una paleta de pintar. A la entrada de la cámara, las placas inclinadas, pero denotando que su posición original fue en pie, tienen ojos y manos (Fig. 9).

Estos hallazgos están mezclados con piedras que en $\mathrm{C} 0.2$ tienen una cierta consistencia. Tanta que creemos que cuando menos en este tramo, se trata de restos de cubierta. De ahí que la capa 5 tenga una subdivisión en 5 a y 5 b. A efectos metodológicos, hablaremos de Nivel III del corredor (5a), equivalente al mismo de la Cámara (capa 7) y Nivel IV del

T. P., 56, n. ${ }^{\circ} 1,1999$ 


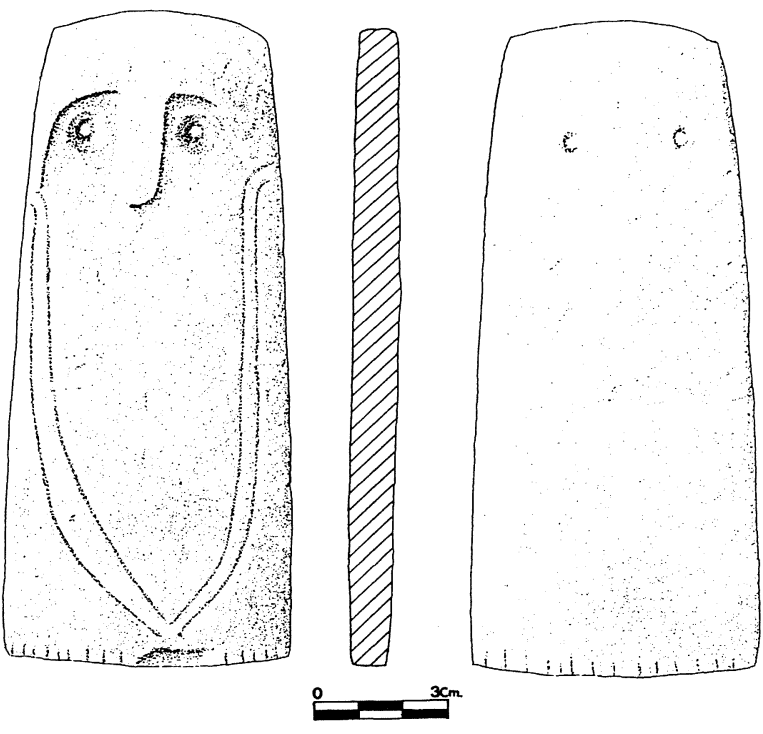

Fig. 9. Placa localizada en el depósito del Corredor de Trincones 1 (Alcántara, Cáceres).

Corredor (5b), IV de la Cámara (capa 8). Es decir a los depósitos menos tocados de la Cámara.

Por último, diferenciamos los materiales literalmente incrustados en la pizarra de la base, al igual que sucede en la capa 9 de la Cámara, como capa 6 del Corredor. Destaca la existencia de una estela antropomorfa (pieza 888). A efectos de interpretación, es nuestro Nivel V, pues en el Corredor no se localizó ningún resto de preparación como el de la capa 7 de la Cámara. Del corredor proceden unas doscientas piezas. La presencia de un brazal de arquero en los niveles más bajos reitera la cronología campaniforme que se derivaba de los fragmentos campaniformes de la Cámara.

Arquitectónicamente, está compuesto por cinco ortostatos de pizarra, según deducimos del alzado del mismo en su sector Norte -el mejor conservado- con una altura máxima de $1 \mathrm{~m}$. que se sitúa junto a la cámara. La altura del corredor desciende hacia su intersección con el atrio, alcanzando en la última pieza $0,60 \mathrm{~m}$. Esto nos permite reiterarnos en nuestra idea de que estos corredores de tan escasa altura, para poder ser utilizados como zona de acceso a la cámara (Bueno Ramírez, 1987b), debieron estar cubiertos únicamente en la zona más próxima a la cámara, es decir en las tres primeras piezas, lo que parece corrobarse con la situación de los restos de cubierta en C 0.2 .

Las demás ejercían el papel de elemento transicional entre las de menor tamaño que delimitan la apertura del atrio y las verticales cubiertas del co- rredor, dando lugar a un espacio abierto y público, en el que también constatamos material arqueológico.

Los objetos documentados en el Atrio son mayoritariamente platos de borde almendrado, fuentes de carena baja, acompañados por algunos pulimentados y escasa industria tallada. Están in situ y deben responder a una cierta actividad en torno al monumento. ¿Quizá ofrendas alimenticias, o un episodio de hábitat en el momento de la construcción del sepulcro? (Bueno Ramírez, 1988).

Estructuralmente, el Atrio está delimitado por varias piezas de pizarra que se disponen de modo trapezoidal en la zona de acceso del monumento (Lám.V). No tienen más de $0,60 \mathrm{~m}$. de ancho y no levantan $0,30 \mathrm{~m}$. Su posición respecto al túmulo no es la vertical absoluta, sino que están echadas en él. El espacio así delimitado es de 3,5 m. en dirección Este y $2 \mathrm{~m}$. en su parte más ancha. Destaca la irregularidad de los laterales que también se ha documentado en Maimón II (Bueno Ramírez et alii, 1998: 178).

Para verificar el modo de factura del Túmulo establecemos varios cortes en su interior, llegando hasta la base en el denominado "Túmulo 3" tras los ortostatos del lateral Norte de la cámara. En él podemos constatar que la talla realizada en la pizarra de base para incrustar los ortostatos incluye una ampliación posterior a estas piezas camerales, en la que se sitúan los contrafuertes traseros de la cámara. Este sistema ya fué documentado por nosotros en la excavación de Maimón I (Bueno Ramírez et alii, 1998: fig. 3).

Sobre una pequeña elevación natural los realizadores del monumento tallan la forma de Cámara y corredor, incluyendo en su "dibujo" espacio

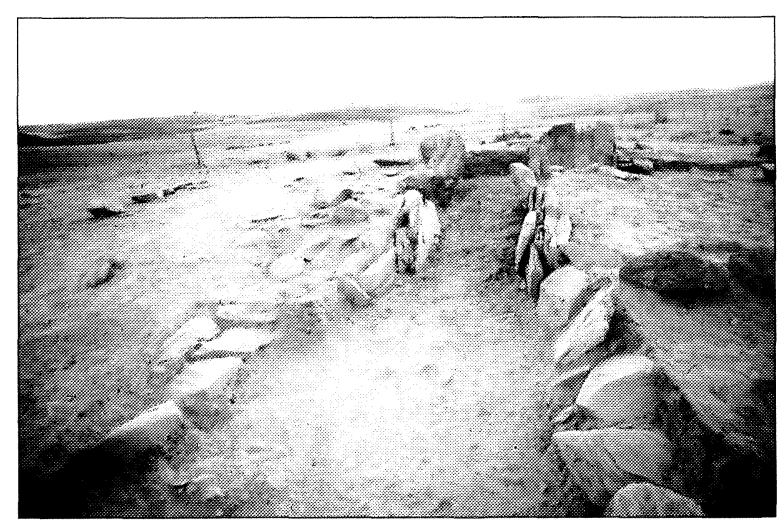

Lám.V. Vista general del dolmen de Trincones 1. En primer plano, el Atrio. Foto R. de Balbín. 

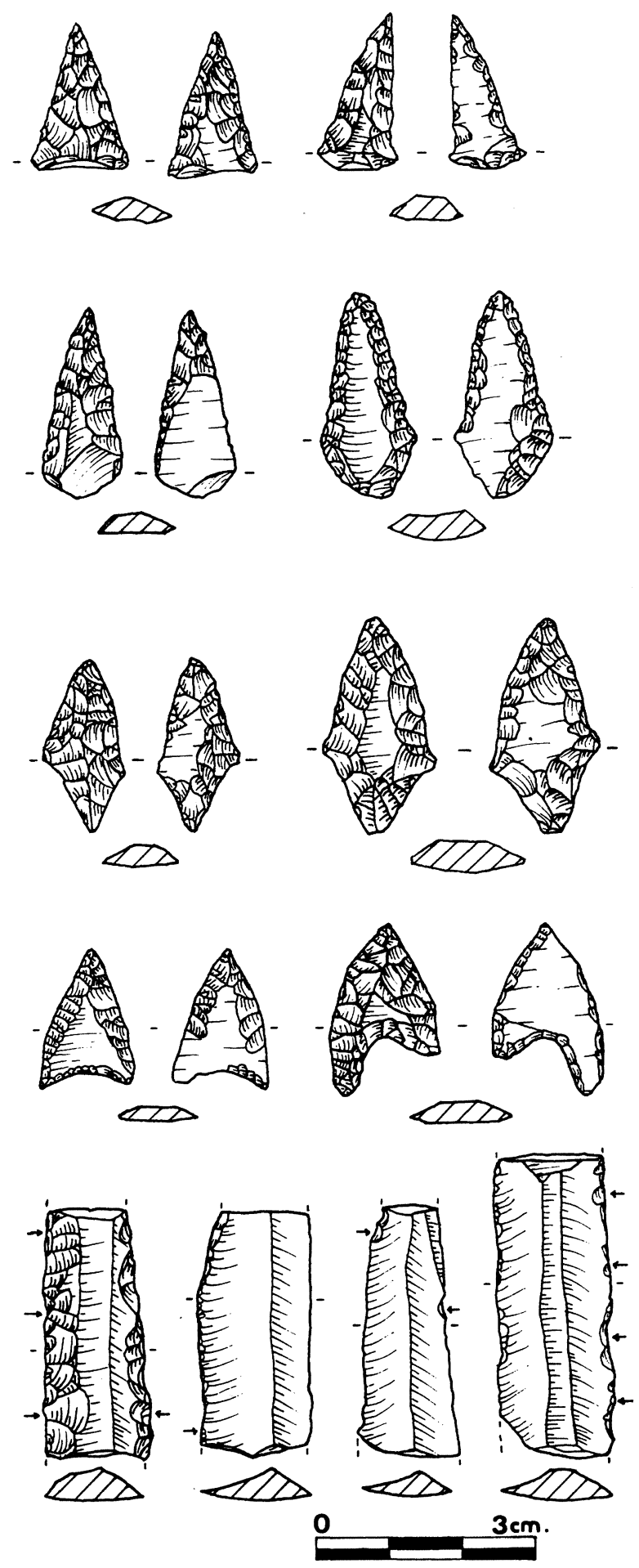

Fig. 10. Industria lítica del dolmen de Trincones 1 (Alcántara, Cáceres)

para insertar los contrafuertes traseros. Posteriormente a este trabajo se levanta el túmulo a base de piedras de pizarra de entre $30 \mathrm{~cm}$. y $50 \mathrm{~cm}$. dispuestas horizontalmente y trabadas sin ningún tipo de argamasa. La altura así conseguida se delimita en el sector Sur con lajas de pizarra de menor tamaño literalmente echadas en el promontorio tumular, mientras que en el sector Norte el cerramiento se ha hecho mediante tres hiladas de lajas de pizarra hincadas, en posición subvertical. La construcción tumular es claramente disimétrica y sus soluciones arquitectónicas son una perfecta adaptación al volumen natural.

Tras la información arqueológica, ambos monumentos fueron consolidados, siguiendo criterios ya expuestos (Bueno Ramírez et alii, 1998: 173).

\section{EL USO DEL ESPACIO FUNERARIO}

Tradicionalmente, el espacio interior de los megalitos formaba parte de la zona reservada a los muertos. El ritual allí desarrollado incluía el depósito de cadáveres y ajuares. Tenemos constatación arqueológica de que no siempre estos depósitos se hacían de la misma manera (Bueno Ramírez, 1991: 106-107). La excavación de Trincones 1 no nos ha proporcionado restos óseos identificables, aunque no descartamos que el suelo de la Cámara contenga algunos restos amortizados.

Lo que sí nos permiten los datos documentados es esbozar un panorama sobre la ubicación de los depósitos al interior del monumento.

En la Cámara, los vasos cerámicos, al igual que las placas, los pulimentados, o los machacadores tienden a situarse en la zona central, concretamente en la fisura natural de la pizarra que recorre parte de ésta y del Corredor. Por el contrario, las puntas de flecha, muy abundantes en la Cámara, aparecen al pie de los ortostatos, en montones bastantes notorios que pueden indicar su depósito original en algún tipo de contenedor de materia orgánica. Las cuentas de collar se encuentran esparcidas por toda la Cámara sin que pueda precisarse una ubicación más concreta de las mismas.

La situación que hemos mencionado plantea la existencia de una ofrenda colectiva en la zona central de la Cámara, a la que se sumarían los collares y las puntas de flecha probablemente como ajuares personales de los enterrados.

La ubicación de los materiales en el Corredor aporta elementos interesantísimos a esta discusión. Uno de los más llamativos es la posición de las estatuillas o placas antropomorfas. En su mayor parte

T. P., 56, n. ${ }^{\circ} 1,1999$ 
están a la entrada de la cámara en pie, reiterando una posición propia de las imágenes antropomorfas en otros contextos megalíticos. Como nosotros planteamos en otro lugar (Bueno Ramírez y Balbín Behrmann, 1994), el megalito es un espacio no sólo fácticamente dividido por elementos arquitectónicos, sino simbólicamente compartimentado. Este universo simbólico se concreta en grafías de distinto tipo sobre los ortostatos y en imágenes antropomorfas que se concentran a la entrada de la Cámara y a la entrada de Corredor o en el Atrio, exactamente como aparecen documentadas en Trincones 1. Las figurillas de la entrada de la Cámara y la estela de la entrada del Corredor poseen su respuesta en el frontal de la Cámara con figuras globulares piqueteadas representando esquemáticos personajes humanos. El eje entre el interior y el exterior del monumento presidido por la imagen humana (Bueno Ramírez y Balbín Behrmann, 1994), es un hecho sin discusión en Trincones 1.

La acumulación de pulimentados en el primer tramo del Corredor es otro dato interesante. Se disponen con una auténtica intención de depósito, al estilo de los que poco más tarde serán reconocidos en otras culturas metalúrgicas. M.Almagro (1962) cita un caso similar en el dolmen del Corchero del conjunto cacereño de Valencia de Alcántara y uno de nosotros ha señalado su presencia en el dolmen de la Estrella (Toledo) (Bueno Ramírez, 1991: 104). Nuevamente, la acumulación en un sector del monumento plantea la existencia de ofrendas colectivas que se añaden a las que podrían considerarse de carácter personal como industria tallada y adornos.

El volumen tumular, en torno a $12 \mathrm{~m}$. de diámetro y casi un metro de altura, en lo hoy conservado, ratifica la situación destacada de esta arquitectura que se ve acrecentada por la presencia próxima de una forma de pequeño tamaño, al estilo de asociaciones similares documentadas tanto a uno como a otro lado de la frontera (Bueno Ramírez, 1994).

Ya hemos mencionado que el alzado máximo de la cámara durante el uso del monumento debía estar en torno al metro y el del corredor, sería menor. Los monumentos de este calibre en el megalitismo del Suroeste peninsular constituyen un episodio muy poco conocido que parece lógico relacionar con fenómenos de emulación de estructuras de mayor tamaño que se están realizando y utilizando en zonas próximas, muy probablemente en momentos contemporáneos.

Los depósitos pudieron abrirse desde la parte superior (Bueno Ramírez, 1994: 48), aunque no es

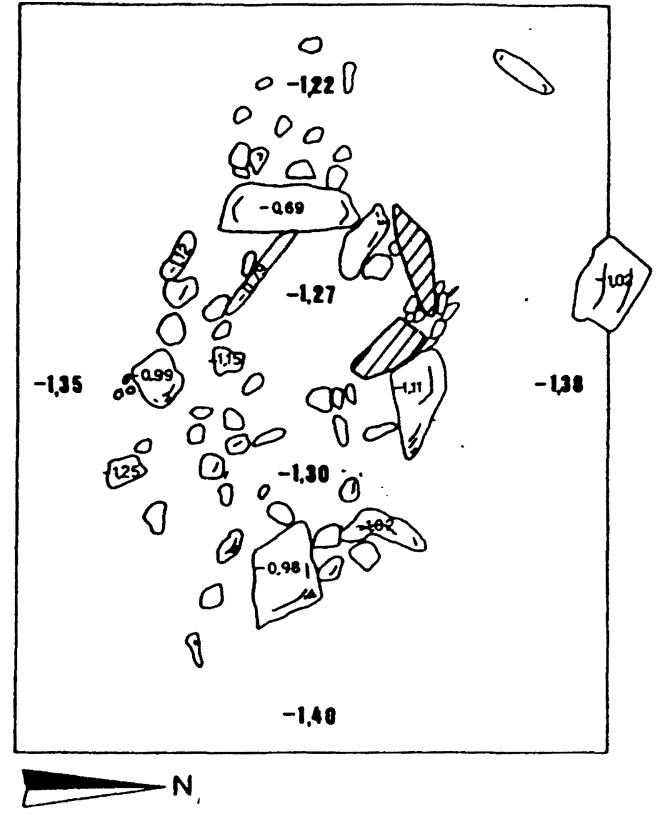

in
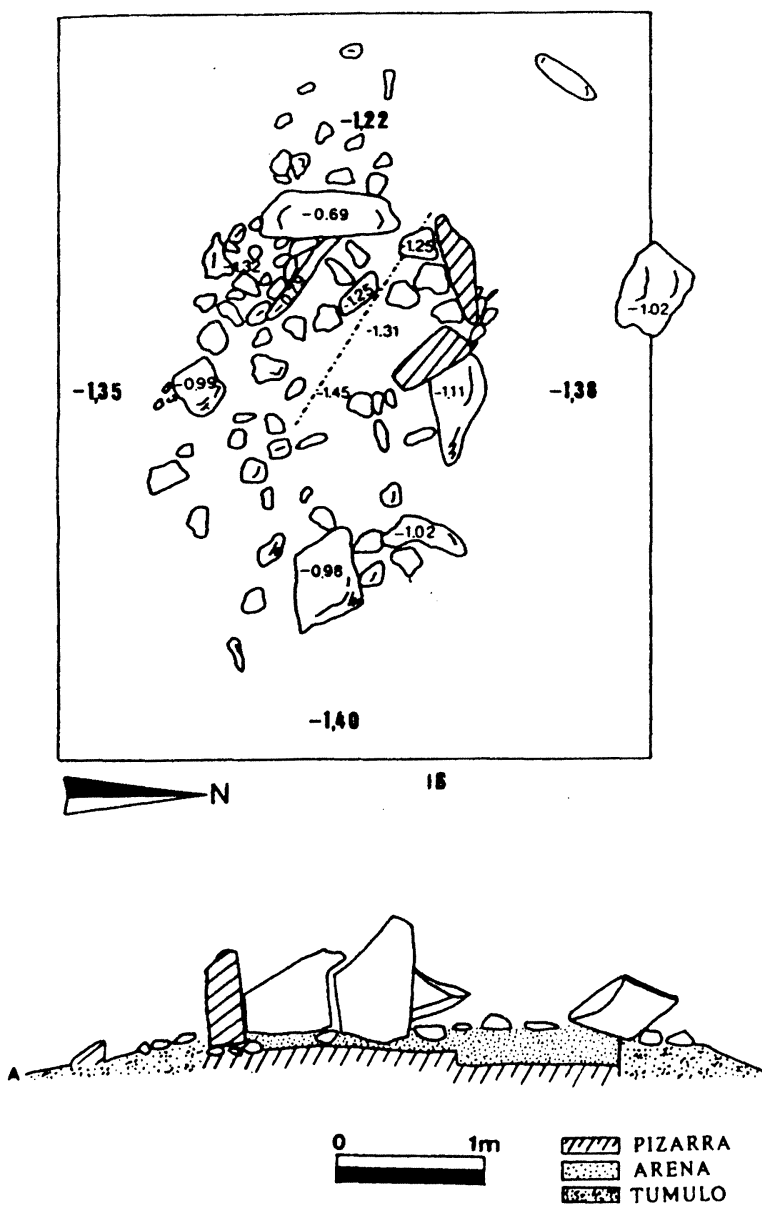

Fig. 11. Plantas y alzados de Trincones II. 
descartable la entrada de una persona físicamente menuda. Aún así, la hipótesis que nos parece más factible es que el monumento se construye y recibe un único depósito, sin que podamos establecer el número de inhumados. La situación del conjunto de pulimentados y de placas a la entrada de la Cámara, certifica que después de realizarse éste no se volvió a tocar. Hecho el depósito se techa la Cámara y el primer tramo del Corredor, quedando abierto el "camino" marcado por el resto del corredor y el Atrio, en el que se resultaría visible la estela antropomorfa. Es ésta una zona abierta en la que se realizan depósitos, probablemente de carácter alimenticio -comida y bebida- lo que explicaría la cantidad de restos cerámicos, o bien es la huella de estancias temporales en el monumento o el testimonio de la habitación mientras se construye.

Si tuviéramos que elegir un paralelo preciso para nuestros monumentos, sólo deberíamos volver la vista hacia la próxima necrópolis de Couto da Espanhola en Rosmaninhal, Portugal, con arquitecturas tan próximas como la de su Anta 2 (Cardoso et alii, 1997).

Los ajuares de Trincones 1 o de Juan Rón I (Bueno Ramírez et alii, 1998) son paralelizables a los de otros sepulcros de mayor tamaño en granito, como Lanchas I, Huerta de las Monjas o Zafra II, en Valencia de Alcántara (Bueno Ramírez, 1988), a excepción del campaniforme. Pero, indudablemente, reflejan la variedad, cantidad y calidad de éstos, por lo que una explicación para los monumentos de menor altura como exponente de unas diferencias sociales (Bueno Ramírez, 1989, 1994; Oliveira, 1997) queda hoy escasa. Es necesario buscar nuevas respuestas. Una que nos parece probable es que estos monumentos de menor altura, sean un modo más, entre el polimorfismo arquitectónico del megalitismo ibérico, de expresar la adaptación al territorio de los grupos humanos que los realizan.

La reiterada búsqueda de un lugar más preeminente para la arquitectura de mayor volumen, se acrecienta en este caso, con el magnífico ajuar documentado y la presencia de Arte Megalítico, confluyendo todos los factores en proponer la existencia de monumentos de mayor prestigio a los que se adosan o se aproximan arquitecturas más pobres a todos los efectos, y muy posiblemente contemporáneas para compartir parte del prestigio detentado por el monumento más destacado.

Estamos hablando, pues, de grupos socialmente similares que se mueven en un territorio con las mismas características a uno y otro lado de la fron- tera. La convivencia de arquitecturas de distinto volumen, con artefactos de prestigio en las mayores, dibuja una sociedad diferenciada con elementos emergentes entroncados con la Jefatura, en la que los grupos familiares y su justificación social de la "herencia" poseen un peso creciente. Sus sepulcros acumulan todos los referentes que el desarrollo diacrónico de la cultura megalítica peninsular ha ido asociando al prestigio y al poder de control de un determinado territorio. Nos referimos a la visibilidad de los túmulos en el paisaje, a la preeminencia de uno o más sepulcros en una necrópolis mayor, a la compartimentación interior del espacio funerario, a la existencia de un sector abierto y público y a la presencia de símbolos gráficos.

\section{AGRADECIMIENTOS}

Como todos los trabajos arqueológicos, el nuestro posee una serie de débitos a instituciones y personas que no queremos olvidar. En primer lugar al Ayuntamiento deAlcántara, cada vez más interesado en rescatar su historia más antigua. D. Pablo Pérez y D. Calixto Agúndez, dos de sus representantes, han colaborado muy directamente en su faceta más fáctica para que estos trabajos hayan podido realizarse. El alcalde, D. Jacinto Cuño, ha apoyado nuestras iniciativas.

La Asociación Amitur ha puesto su empeño e ilusión mayor en llevar adelante un campo de trabajo de universitarios de Cáceres y Alcalá de Henares, dirigido por Dña. Belén Solano y Dña. María JoséAcosta. Su actuación ha sido fundamental y esperamos seguir colaborando en próximas campañas.

El trabajo diario ha sido realizado por los firmantes de este estudio, bajo la dirección de P. Bueno Ramírez y R. Barroso Bermejo, con la ayuda de alumnos y alumnas de las mencionadas universidades, además de jóvenes de la comarca de Alcántara en ese momento contratados en la Escuela Taller de Arqueología, a cargo de C. Montano. De todos ellos queremos dejar constancia: Juana Álamo Moya, MiriamAlhambra Moreno-Arrones, Mónica Borrega Granados, Ana I. Cano Ortiz, Laura Calvo Olmeda, Enrique Cerrillo Cuenca, Raquel Expósito Capilla, Gema Forner Estévez, Laura Fortea Manzanares, Guadalupe Galván Durán, Lourdes Gálvez Pérez, M. Soledad Gálvez Pérez, Rafael Fuentes García, Diego Garcia-Setién, Yvette Garrigós Corrales, Begoña GómezAmado, María Gordejo Ca-

T. P., 56, n. ${ }^{\circ} 1,1999$ 
nal, Celia Hidalgo Calvino, Gloria Holgado Barroso, Mario Igualador Castilla, Juan M. Loiro Ortega, Ángel L. Manso Iglesias, Víctor Martínez Palacios, Cristina Navarro Martín, $\mathrm{M}^{\mathrm{a}}$ Ángeles Nevado Mogena, Juan Francisco Pascua Turrión, Javier Parralejo Almodóvar, Yolanda Pereira Ramos, Alicia Prada Gallardo, Pilar Regalado Borrego, $\mathrm{M}^{\mathrm{a}}$ Carmen Rodríguez Díaz, Elena RodríguezTen, Roque Rojas Martín, Eduardo Ruiz Bautista, Antonio Vázquez Cuesta y José F. Velasco Pagán.

En el local del Instituto de Enseñanzas Medias San Pedro deAlcántara, a cuyos responsables queremos agradecer sus facilidades, se dormía y se trabajaba con el material, además de que también comíamos allí, gracias al ingenio y gusto culinario de Dña. Rosario Almeida Salvado.

La campaña se desarrolló en el mes de Julio de 1998 y queremos agradecer a los dueños del terreno, los hermanos Arnaiz, las facilidades que nos dieron para realizar nuestro cometido. Igualmente debemos hacer patente la amabilidad de los dueños de las fincas colindantes que no objetaron nada a nuestro paso diario.

\section{BIBLIOGRAFÍA}

Almagro Basch, M. (1962): Megalitos en Extremadura I y II. Excavaciones Arqueológicas en España, 3 y 4. Madrid.

Bodega Fernández, M.I. y Gutiérrez Ronco, S. (1978): Memoria del conjunto provincial. Escala 1: 200.000. Cáceres. Instituto Geográfico Nacional. Madrid.

Bueno Ramírez, P. (1987a): Megalitismo en Extremadura. Tesis doctoral inédita. 3 vols. Universidad Complutense. Madrid.

- (1987b): Megalitismo en Extremadura. El Megalitismo en la Península Ibérica. Ministerio de Cultura. Madrid: 45-50.

- (1988): Los dólmenes de Valencia de Alcántara. Excavaciones Arqueológicas en España, 155. Madrid.

- (1989): "Cámaras simples en Extremadura".XIX Congreso Nacional deArqueología, I. Zaragoza: 385-397.

- (1991): Megalitos en la Meseta Sur: los dólmenes de Azután y la Estrella (Toledo). Excavaciones Arqueológicas en España, 159. Madrid.

- (1992): "Les plaques décorées alentejaines: approche de leur étude et analyse". L'Anthropologie, 96(2-3): 573-604.

- (1994): "La necrópolis de Santiago de Alcántara (Cáceres). Una hipótesis de interpretación para los sepulcros de pequeño tamaño del megalitismo occidental". Boletin del Seminario de Estudios de Arte y Arqueología. LX: 25-100.
Bueno Ramírez, P. y Balbín Behrmann, R. de (1992): "L'art mégalithique dans la Péninsule Ibérique. Une vue d'ensemble". L'Anthropologie, 96(2-3): 499-572.

- (1994): "Estatuas-menhir y estelas antropomorfas en megalitos ibéricos. Una hipótesis de interpretación del espacio funerario". Homenaje a Echegaray. Museo y Centro de Investigaciones de Altamira. Monografías, 17: 337-347.

- (1996): "El papel del elemento antropomorfo en elArte megalítico ibérico". Revue Archéologique de l'Ouest, 8: 41-64.

- (1999): “Arte Megalítico en sepulcros de falsa cúpula. A propósito del monumento de Granja de Toniñuelo (Badajoz)". III Congreso Internacional de Arte Megalítico. Brigantium. La Coruña.

Bueno Ramírez, P.; Balbín Behrmann, R. de; Barroso Bermejo, R.;Aldecoa Quintana, M. ${ }^{\mathrm{a} A}$. y Casado MaTEOS, A.B. (1998): "Dólmenes en la Cuenca del Tajo: restauración y consolidación de megalitos en Alcántara (Cáceres)". Trabajos de Prehistoria, 55(1): 171-183.

- (e.p.): "Sepulcros megalíticos en el Tajo: excavación y restauración en dólmenes deAlcántara (Cáceres. España)". Ibn Maruan. Evora.

Cardoso, J.L.; Caninas, J.C. y Henriques, F. (1997a): “A Anta 2 de Couto da Espanhola (Rosmaninhal, Idanhaa-Nova)". Estudos Pré-Históricos, V: 9-28.

- (1997b): "Contributos para o conhecimento do megalitismo na Beira Interior (Portugal): a regiao do Tejo Internacional". En: R. de Balbín Behrmann, P. Bueno Ramírez (eds.): Actas del II Congreso Peninsular de Arqueología. T. II: Neolítico y Calcolítico. Fundación Rei Afonso Henriques. Zamora: 207-215.

Esteban Ortega, J.; Sánchez Abal, J.L. y Fernández CoRRALES, J.M. ${ }^{a}$ (1988): La necrópolis del castro del Castillejo de la Orden, Alcántara (Cáceres). Consejería de Educación y Cultura. Univ. Extremadura. Cáceres. 104p., XIV láms.

FLorido LARAÑA, P. (1987): La minería en Extremadura. Junta de Extremadura. Mérida

Guillén Oterino, A. (1983): "Sobre la introducción del castaño, Castanea sativa, en el Mediterráneo occidental". Zephyrus, XXXIX-XXXV.

Henriques, F.; Caninas, J.C. y Chambino, M. (1993): Carta Arqueológica do Tejo Internacional, 3. Vila Velha de Rodao.

LEISNER, G. y V. (1951): Antas do concelho de Reguengos de Monsaraz. Instituto para o Alta Cultura. Lisboa.

LóPEz, P. (1994): “Análisis polínicos”. En P. Bueno Ramírez: La necrópolis de Santiago de Alcántara (Cáceres). Una hipótesis de interpretación para los sepulcros de pequeño tamaño del megalitismo occidental. Boletin del Seminario de Estudios de Arte y Arqueología, LX: 97-100.

Mapa Metalogenético de España. E. 1:1, 500. 000. 1972. Mapa previsor de mineralizaciones de cobre. Instituto Geológico y Minero de España. Madrid. 
Martínez de Pisón, E. (1977): Los paisajes naturales de Segovia, Ávila, Toledo y Cáceres. Madrid.

Montano Domínguez, C. (1987): "Aproximación al estudio de los sepulcros megalíticos de Alcántara (Cáceres)". Anales de laAsociación de Estudios Comarcales: 2958. Cáceres.

Montano Domínguez, C. y Iglesias Álvarez, M. (1988): Grabados rupestres en Alcántara (Cáceres). Ayuntamiento deAlcántara.

Oliveira, J. (1997): Sepulturas megalíticas del término municipal de Cedillo. Provincia de Cáceres. Ayuntamiento de Cedillo.

Ramos, J. y Giles, F. (1996): El dolmen de Alberite (Villamartin). Aportaciones a las formas económicas de las comunidades Neolíticas del Noroeste de Cádiz. Cádiz. SÁNCHez PalenCIA, F.J. (1989): "La explotación del oro en la Hispania romana: sus inicios y precedentes". Minería y metalurgia en las antiguas civilizaciones mediterráneas y europeas, II. Ministerio de Cultura. Madrid: 35-53.

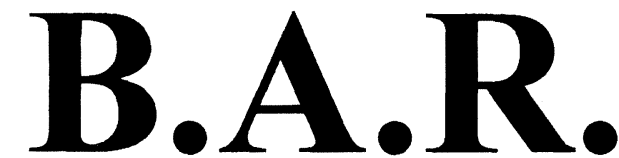

We need good manuscripts

\section{John and Erica Hedges \\ British Archaeological Reports \\ 7 Longworth Road \\ Oxford OX2 6RA, England \\ $\mathrm{Tel} / \mathrm{Fax}+44(0) 1865511560$}

E-mail: bar.hedges@lineone.net

BARs are sold by Hadrian Books who send free catalogues Tel/Fax: +44 (0)1865316916 BARs are also published by Archaeopress.

\section{B.A.R. RECENT SPANISH TITLES}

BAR S713, 1998 The Palaeoecology of Lower Magdalenian Cantabrian Spain by James T. Pokines. $£ 38.00$

BAR S714, 1998 An Archaeometallurgical Survey for ancient Tin Mines and Smelting Sites in Spain and Portugal Mid-Central Western Iberian Geographical Region 1990-1995 by Craig Merideth. $£ 46.00$

BAR S724, 1998 Elites y organización de la religión en las provincias romanas de la Bética y las Mauritanias: sacerdotes y sacerdocios by José A. Delgado Delgado. $£ 44.00$ BAR S729, 1998 Las importaciones de vajilla fina de barniz negro en la Cataluña sur y occidental durante el siglo III aC Comercio y dinàmica de adquisición en las sociedades indigenas by Jordi Principal-Ponce. Western Mediterranean Series 2. $£ 40.00$

BAR S732 1998 El Hábitat Mesolítico en el Cantábrico Occidental: Transformaciones Ambientales y Medio Fisico durante el Holoceno Antiguo by Miguel Ángel Fano Martínez. $£ 38.00$

BAR S736 1998 Arqueología Experimental: La manufactura de Terracotas en Época Romana by $\mathrm{M}^{\mathrm{a}}$ Luisa Ramos Sáinz and Luis Fuentes Ghislain. £25.00.

BAR S742 1998 Estudio geoarqueológico de los asentamientos prehistóricos del Pleistoceno Superior y el Holoceno inicial en Catalunya by M. Mercè Bergadà Zapata. $£ 49.00$. 